with a cis-fusion (cf. VI). The complete configuration of rotenone is thus $\left(6 a S, 12 a S, 5^{\prime} R\right)$ as in (V).

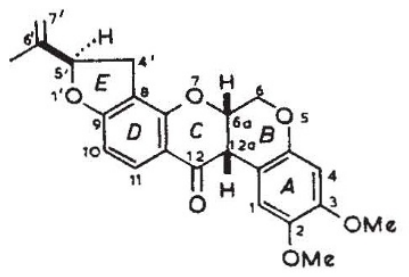

(v)

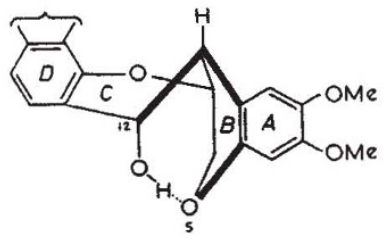

VI
Dr. W. D. Ollis, University of Bristol, spoke on the relative configuration of the rotenoids.

In collaboration with Prof. Carl Djerassi (Stanford University), it has been shown that the absolute stereochemistry of the eight natural rotenoids is closely related to that of rotenone (V). They all have the same relative stereochemistry at $\mathrm{C}_{6 a}$ and $\mathrm{C}_{12 a}$; sumatrol and rotenone also have the same stereochemistry at $\mathrm{C}_{5^{\prime}}$. These stereochemical relationships have been established by optical rotatory dispersion studies on natural rotenoids and on derivatives of rotenone which were selected in order to assess the contributions of $\mathrm{C}_{6 a}, \mathrm{C}_{12 a}$ and $\mathrm{C}_{5^{\prime}}$.

This work is complementary to that of Crombie and Büchi described in the preceding paper on the determination of the absolute stereochemistry of rotenone and indicate that the biosynthesis of the rotenoids is highly stereoselective. The stereochemical relationship between flavanoids, isoflavanoids and rotenoids, and possible biosynthetic implications were discussed.

Prof. D. H. R. Barton (Imperial College of Science and Technology, University of London) described alkaloid synthesis.

The biogenesis of many plant products may proceed through the oxidative coupling of phenolic precursors. In recent years several successful chemical syntheses have been based on this biogenetic idea; for example, oxidation of methylphloracetophenone and dehydration of the product gave the mould metabolite, usnic acid. Certain alkaloids may also be derived in principle by oxidation of suitable phenolic intermediates, the morphine group providing a particularly attractive example.

The structure of the Amaryllidaceae alkaloid galanthamine (VIII) was predicted on biogenetic grounds, and a chemical synthesis has now been completed. The hypothetical phenolic precursor was synthesized and its oxidation by a variety of reagents studied. Polymerization occurred readily but it was eventually possible to isolate the desired $\alpha, \beta$-unsaturated ketone, narwedine (VII), in low yield. Reduction of narwedine gave a mixture of epimeric alcohols one of which was shown to be racemic galanthamine. A comparison of the physical properties of galanthamine and epigalanthamine showed that the hydroxyl group in galanthamine is hydrogen bonded to the ether ring oxygen atom, thus establishing the stereochemistry of these alkaloids. Narwedine racemized readily in hydroxylic solvents but crystallization of a mixture of $( \pm)$-narwedine (VII) and (-)-galanthamine (VIII) from ethanol gave (t)-narwedine. A study of this unusual phenomenon has led to the resolution of narwedine and galanthamine.<smiles>CCCC12C=CC(=O)CC1Oc1c(OC)cccc12</smiles>

(VII)

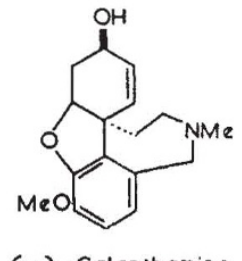

(VIII)
The biogenesis of Amaryllidaceae alkaloids is at present being investigated using precursors labelled with carbon-14. Preliminary experiments show that both tyrosine and the phenolic intermediate are incorporated into galanthamine in King Alfred daffodils. BEN BROWN

1 Annalen, 627, 229 (1959).

s Proc. Chem. Soc., 280 (1960), and unpublished work.

\title{
INTERNATIONAL CONVENTION ON STARCH
}

$\mathrm{T}$ HE annual International Starch Conference was once again held at Detmold, during April 26-28, and was attended by nearly 300 chemists from 25 nations. Twenty-five papers were presented to the meeting and they were classified as follows: (1) starch research; (2) industrial research; (3) derivatives.

A series of beautiful colour microphotographs were exhibited by Dr. A. H. Czaja (Aachen), showing the manner in which starch granules gelatinize in water. When suspended in a strong salt solution in the presence of $I_{2}-K I$ the blue amylose fraction was seen to bleed out of the granule, leaving the violet amylopectin behind in the intact structure. No such bleeding of amylose was observed when the reaction was carried out in iodine-saturated water. Here the whole granule was stained violet throughout. When the granule was then damaged slightly by rubbing with a glass rod, the amylose blue colour was seen to develop. Potato, maize and rice starch behaved similarly.
When using a fluorescence dye, small starch granules were seen to fluoresce strongly (red) while large granules showed a weak green colour. No explanation of this behaviour, which is opposite to that expected, is yet known.

Acridine orange showed that granules of wheat starch were surrounded by a thin film of protein.

The renewed interest in the degradation of starch by physical means was discussed by S. Augustat (Potsdam-Rehbruecke), who had used a vibratory ball mill. In this machine the vessel does not rotate, but contains a large number of balls which are agitated with a frequency of 1,420 vibrations per min. The amplitude of the vibrations is about $2 \mathrm{~mm}$., and the powder in the mill is kept in circulation by the airstream generated by the balls. After treating potato starch in such a mill for $5 \mathrm{hr}$. complete solubility in cold water was achieved together with a strong rise in reducing power. It was considered that this process may possibly have a future practical application. 
The quantitative estimation of ether and ester groups in starch derivatives was described by Dr. R. J. van der Bij (Foxhol, Holland). A thin film of starch was cast on 'Pliofilm' and after removal the film was pressed between plates of rock salt. The estimation was carried out with the infra-red spectroscope, which gave a characteristic absorption band at $5 \cdot 8 \mu$. The intensity of the absorption was proportional to the degree of substitution, but a correction for the thickness of film had to be made.

The problems which arise through automation in the starch-producing industry were described by $\mathrm{H}$. Runge (Hamburg). The starch industry is peculiar in that certain processes do not lend themselves to automation, so that an operative may be called on to perform his work in the conventional manner as well as by instrumentation. The main problem encountered in this industry was the education of a new generation of operatives who were able and willing to perform their tasks in this way.

A. Malyjev (Central Research Institute for the Starch and Starch-syrup Industry, Moscow) explained the use of the dextrose-sodium chloride double salt to facilitate the crystallization of dextrose in factories in the U.S.S.R. Dextrose syrup at $56^{\circ}$ Brix was treated with 0.2 per cent sodium chloride $(\mathrm{w} / \mathrm{w})$ at $20^{\circ} \mathrm{C}$. Crystallization was completed after $8 \mathrm{hr}$., and it was found that this was a much shorter period than experienced when crystallizing dextrose in the usual manner. The crystals obtained were larger and the yield ( 85 per cent) higher than normal. After crystal. lization the double salt was filtered off and decomposed in a syrup of $22^{\circ}$ Brix, which had been cooled to $10^{\circ} \mathrm{C}$.

The effect of certain cations on starch was discussed by G. Tegge and W. Kempf (Detmold) and Dr. S. Winkler (Berlin). Calcium and magnesium ions (such as occur in hard water) were found to lower the viscosity of starch pastes to a greater degree than sodium or potassium ions. It was maintained that the phosphoric acid ester of starch forms salts with these cations. It was claimed that the only true viscosity value could be obtained by having the ester in the free-aoid form (called hydrogen starch). This form of starch was produced by washing the native, ungelatinized starch with $N / 100$ hydrochloric acid for 10 min., followed by washing with distilled water for half an hour to remove the acid. Hydrogen starch was said to be unstable owing to slow autohydrolysis.

K. Pasirouk (Central Research Institute for Starch and Starch-syrup Industry, Moscow) described a new potato washing machine in use in Russian starch factories. Potatoes were freed from sand and grit by being shaken violently at 3,000 cycles/min. in a long stationary cylinder, through which a swift current of water passed. Potatoes vibrated with an amplitude of $5 \mathrm{~mm}$. The machine dealt with 200 tons a day, each charge being $470 \mathrm{kgm}$.

A full account of the papers outlined above and of the remaining papers, together with the discussions which followed in each case, will be published in the journal Die Stärke in due course. $\quad \mathrm{E}$. Dux

\section{THE NATIONAL INSTITUTE FOR RESEARCH IN DAIRYING}

$\mathbf{T}^{\mathrm{T}}$ is not always realized that the United Kingdom has one of the largest dairy industries in the world. Milk production in this country now exceeds 2,000 million gallons a year, and the milk has a value to the consumer of about $£ 450$ million, an amount of production which far exceeds that of many other well-known dairying countries such as New Zealand, Denmark and Holland. This vast and progressive British industry is continually increasing in efficiency, and much of the progress being made is directly attributable to the work done at the National Institute for Research in Dairying, the annual report of which for 1960 is now available*.

The Institute has grown greatly since the War. It now consists of ten main research departments, and has a staff of about 400 of whom some 30 per cent are members of the scientific and experimental officer grades.

The scope of the Institute's research programme is very great, ranging, as the report shows, from a study of many widely differing practical problems such as the use of slatted floors in the housing of dairy cattle and the types of chemical agents that can be approved for cleaning dairy equipment to basic scientific studies such as those of the Physiology Department on the pituitary gland and lactation, the biochemical properties of mammary gland mitochondria and the isolation, chemical structure and biological properties of the œstrogen mirœstrol.

No more than one or two of the many investigations now in progress can be referred to here. One particu-

* National Institute for Research in Dairying. Report 1960. Pp 164. (Shinfield: National Institute for Research in Dairying: University of Reading, 1961.) larly interesting example is concerned with the allimportant question of the composition of milk on which, of course, the nutritive value of milk and milk products depends. It is now well known that much of the dietary energy absorbed by ruminants is absorbed in the form of the lower fatty acids which are produced in the rumen in different proportions from different types of feeding-stuffs. Collaborative work between two of the Institute's main research departments has shown that when isocaloric amounts of the lower fatty acids are given separately by ruminal infusion to lactating cows acetic acid increases not only the milk yield but also the fat percentage in the milk and the yields of fat, protein and lactose, whereas propionic acid has no effect on milk yield but increases the percentage of protein and decreases the percentage of fat. Butyric and lactic acids have no effect on milk yield but butyric acid increases fat percentage and lactic acid increases protein percentage. This type of information is already leading to a much better understanding of the factors that affect the composition of milk, and when further extended it should make it much easier than it is to-day to influence the composition of cows' milk within certain limits by suitable changes in the rations fed to the cows, a development which could be of farreaching significance in the dairy industry.

Some of the other outstanding advances that are being made depend on the application of relatively new scientific methods to dairy problems. Work is being done, for example, on the differentiation and recognition of various strains and species of bacteria by paper chromatographic procedures, and the method is being applied in a detailed study of the 